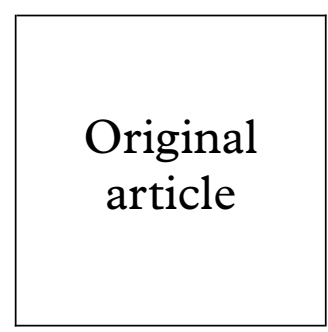

Department of Sexually Transmitted Diseases

R F Miller

\section{Department of \\ Virology}

N S Brink

Department of Histopathology, Division of Pathology and Infectious

Diseases

S B Lucas

\section{Department of}

Neurology

M J G Harrison

Department of Medical Physics and Bioengineering I D Wilkinson

Institute of Nuclear Medicine, University College London Medical School, London W1P 7PN

D C Costa

P J Ell

Department of Imaging, University College London Hospitals (NHS) Trust, London W1N 8AA

M A Hall-Craggs

B E Kendall

Department of Neuropathology, Institute of Neurology, Queen Square, London WC1N 3BG

F Scaravilli

Correspondence to: Dr R F Miller, Department of Sexually Transmitted Diseases, Division of Pathology and Infectious Diseases, UCL Medical School, Mortimer Market Centre, Mortimer Market (Off Capper Street), London WC1E 6AU.

\title{
Magnetic resonance imaging, thallium-201 SPET scanning, and laboratory analyses for discrimination of cerebral lymphoma and toxoplasmosis in AIDS
}

\author{
R F Miller, M A Hall-Craggs, D C Costa, N S Brink, F Scaravilli, S B Lucas, \\ I D Wilkinson, P J Ell, B E Kendall, M J G Harrison
}

\begin{abstract}
Objectives: To compare the results of magnetic resonance imaging (MRI) and thallium-201 $\left({ }^{201} \mathrm{Tl}\right)$ SPET scanning with laboratory analyses including CSF DNA detection, brain biopsy, and necropsy in the discrimination of cerebral lymphoma and toxoplasmosis in patients with AIDS. Methods: A retrospective study of 32 patients infected with HIV who had focal CNS lesions on MRI as a result of either lymphoma or toxoplasmosis.

Results: 18 patients had lymphoma, 12 had toxoplasmosis, and two had both. Toxoplasma IgG antibodies were detected in only seven patients - four with toxoplasmosis, two with lymphoma, and one with both diagnoses. Epstein-Barr virus DNA was detected in CSF of all six patients with lymphoma and none of two with toxoplasmosis. MRI showed multiple lesions in 23 patients, appearances did not discriminate between lymphoma and toxoplasmosis; nine patients had single lesions, of these eight had lymphoma ( $p=0.044$, two tailed Fisher's exact test) ${ }^{201}$ Tl SPET showed accumulation in 17 with lymphoma and six with toxoplasmosis ( $p=0.034$, two tailed Fisher's exact test). Of nine patients with single lesions on MRI and ${ }^{201} \mathrm{Tl}$ SPET with focal accumulation eight had lymphoma. ${ }^{201} \mathrm{Tl}$ SPET uptake ratios of $\geqslant 2.9$ were only seen with lymphoma.

Conclusion: Knowledge of patients' toxoplasma serostatus does not aid discrimination between lymphoma and toxoplasmosis. Single lesions on MRI with focal accumulation of ${ }^{201} \mathrm{Tl}$ strongly suggest lymphoma. Multiple lesions on MRI with ${ }^{201} \mathrm{Tl}$ SPET uptake ratios $\geqslant 2.9$ also suggest lymphoma; uptake ratios less than 2.1 do not aid discrimination. Detection of Epstein-Barr virus DNA in CSF is highly sensitive and specific for cerebral lymphoma. (Sex Transm Inf 1998;74:258-264)
\end{abstract}

Keywords: lymphoma; toxoplasmosis; magnetic resonance imaging; thallium-201; SPET

\section{Introduction}

Neurological dysfunction has been reported as a clinical manifestation of AIDS in $39-70 \%$ of patients. ${ }^{1-3}$ Whereas both human immunodeficiency virus (HIV) itself and opportunistic infection by cytomegalovirus (CMV) may cause diffuse CNS disease, ${ }^{4-6}$ encephalitis due to Toxoplasma gondii is the most frequent cause of focal CNS disease, accounting for up to $70 \%$ of such cases. ${ }^{7}$ CNS lymphoma, although very uncommon in the general population, occurs in approximately $5 \%$ of patients with AIDS in industrialised countries. ${ }^{8}$

Other causes of focal lesions include cryptococcomas, tuberculous abscesses, and metastatic tumours. The clinical presentation of patients with focal CNS lesions caused either by $T$ gondii or CNS lymphoma is indistinguishable and the neuroradiological abnormalities demonstrated by computed tomography (CT) or magnetic resonance imaging (MRI) frequently fail to discriminate between the two diagnoses. ${ }^{910}$ Although a tissue diagnosis may be made by a stereotactic brain biopsy most centres do not routinely perform this procedure. Instead, patients with focal CNS lesions are treated empirically with anti- $T$ gondii drugs, a clinical and imaging response to therapy being diagnostic. Brain biopsy is then reserved for those patients who fail to respond to therapy or who have neuroradiological features at presentation that are atypical. Brain biopsy is invasive, requires the availability of a neurosurgical department, and in HIV infected patients has an associated surgical morbidity (up to $12 \%$ ) and mortality (up to $2 \%$ ). ${ }^{11}$ Sampling errors, especially in those with multiple lesions, mean the procedure is non-diagnostic in between $5-33 \%$ of cases. ${ }^{12}$

In order to aid diagnostic discrimination without the need for brain biopsy, alternative diagnostic tests have been used. Detection of Epstein-Barr virus (EBV) DNA in CSF by the polymerase chain reaction (PCR) has been shown to be a highly sensitive and specific technique for diagnosis of CNS lymphoma in AIDS. ${ }^{13} 14$ In contrast, detection of $T$ gondii DNA in CSF by PCR has only moderate sensitivity. ${ }^{14}{ }^{15}$ Because of contraindications to lumbar puncture including mass effect, or midline shift, CSF examination is not always possible, thus limiting the diagnostic usefulness of this molecular technique. Alternative imaging methods have been used including MRI spectroscopy, which also fails to discriminate between $T$ gondii abscesses and lymphoma, ${ }^{16}$ and single photon emission tomography (SPET) using thallium-201 $\left({ }^{201} \mathrm{Tl}\right) \cdot{ }^{17-19}$ In the general population ${ }^{201} \mathrm{Tl}$ SPET imaging has been used to localise brain tumours: tumour 
uptake is unrelated to increased cell membrane permeability and is independent of glucocorticoid administration. ${ }^{201} \mathrm{Tl}$ does not accumulate in non-neoplastic lesions such as infection and radiation necrosis. ${ }^{20}$ In AIDS patients ${ }^{201} \mathrm{Tl}$ SPET imaging has been shown in some studies to aid discrimination between CNS lymphoma and $T$ gondii causing focal CNS lesions. ${ }^{17-19} 21$

We undertook a retrospective study of 32 HIV positive patients presenting with focal CNS lesions in whom we compared the radiological diagnosis made by MRI and by ${ }^{201} \mathrm{Tl}$ SPET scanning with that made by laboratory analyses including CSF PCR, brain biopsy, and necropsy.

\section{Methods}

We identified 32 patients with HIV presenting to University College London Hospital with focal CNS lesions between March 1993 and December 1996 who underwent clinical assessment including cranial MRI and ${ }^{201} \mathrm{Tl}$ SPET scanning. During the study period a total of $302 \mathrm{HIV}$ infected patients had MRI.

Of the 32 patients studied 29 were men (all were white and homosexual) and three were women (two were white, one was of African origin, all were heterosexual). Their ages ranged from 27 to 55 (median 36) years. CD4 lymphocyte counts ranged from 0-0.09 (median $0.02) \times 10^{9} / 1$ (normal range $0.35-2.2 \times 10^{9} / 1$ )

At the time of their neurological presentations all patients had been admitted under the care of an HIV/AIDS specialist (RFM) and were also seen by a neurologist $(\mathrm{MJGH})$; they were investigated according to a unit protocol. Following a clinical assessment, investigations included measurements of IgG antibodies to $T$ gondii using a latex agglutination assay (Eikin, Mast Diagnostics). In those with positive results (titre $>1: 16$ ) samples were sent to the toxoplasmosis reference laboratory for detection of IgG antibodies by the Sabin-Feldman dye test and measurement of $\operatorname{IgM}$ antibodies by a particle agglutination assay (Toxo-ISAGA; Bio Mérieux). Note was also made of patient's use of co-trimoxazole for prophylaxis of Pneumocystis carinii pneumonia (PCP).

Cranial MRI was performed at 1.5 Tesla on a standard clinical system (Siemens Magnetom 63 SP, Erlangen, Germany), using a protocol as previously described. ${ }^{6}$

The cranial MRI scans of the 32 patients were re-reported, mixed in with scans from patients matched for CD4 lymphocyte count who had also presented with neurological symptoms and signs and whose MR scans showed focal lesions, by two radiologists (MHC and BK) who were experienced in interpreting cranial MRI of patients with HIV. Scans were reported independently by the two radiologists: when there was disagreement consensus was reached in conference. The radiologists were blinded to the subject's clinical and pathological diagnoses, and also to who was included in the study. Predetermined criteria were used to report the MRI; in particular the number and anatomical location of lesions, their size, the degree of surrounding oedema, and the presence and nature of any enhancement was noted.

SPET of the brain was performed 30 minutes after injection of $3 \mathrm{mCi}(111 \mathrm{MBq})$ of ${ }^{201} \mathrm{Tl}$ intravenously. ${ }^{17}$ Patients were studied with one of two brain imaging instruments, either the SME (Strichman Medical Equipment) 810 brain dedicated tomograph (19 patients) or the GE (General Electric) Optima (13 patients). Data acquisition and reconstruction followed standard protocols. For the SME slice thickness was $1.25 \mathrm{~cm}$ and reconstruction was performed using an iterative method using filters set automatically by the manufacturer. For the Optima slice thickness was 2 pixels $=8 \mathrm{~mm}$ and prefiltering was performed using a Hanning filter with a frequency of $0.8 \mathrm{cycles} / \mathrm{cm}$, followed by standard ramp projection filter. Attenuation correction was performed using manufacturer's algorithms. All SPET images were interpreted by an experienced nuclear medicine physician (DCC) who was "blinded" to the patient's presumptive diagnosis. An initial qualitative (visual) assessment was carried out directly from the computer display.

In each patient where focal accumulation of ${ }^{201} \mathrm{Tl}$ was seen anatomical correlation with focal lesions on MRI was performed and quantitative analysis was carried out using transaxial SPET slices. Square (GE Optima) or circular (SME 810) regions of interest (ROI) were used to obtain average radioactivity counts in each of the focal accumulations of ${ }^{201} \mathrm{Tl}$ and in normal brain tissue. For calculations of average counts in the lesions all the slices showing radioactivity counts above $50 \%$ of the maximum in each ${ }^{201} \mathrm{Tl}$ SPET focal abnormality were used. For background/normal brain tissue five ROI per slice (minimum of five slices) were used; sampling was done from areas within the same regions in the contralateral brain, unless there was a further lesion in that site, in which case other unaffected regions were selected. Background ROI were not chosen by selecting the lowest areas of contralateral uptake and particular care was taken to avoid highly vascular structures - that is, the scalp, meninges, and vessels in the base of the brain and the (sagittal and transverse) sinuses. The size of the ROI of both methods was consistent for both lesions and background. An uptake ratio was calculated for each ${ }^{201}$ T1 SPET focal abnormality from the ratio of activity in the lesion to the averaged background/normal brain tissue activity.

Lumbar puncture was performed in those patients without a contraindication (such as mass lesion or midline shift present on MRI). In addition to routine biochemical, microbiological, and cytological analyses tests for antibodies to $T$ gondii were carried out (as described above). An aliquot of CSF was analysed at the same time for the presence of EBV, $\mathrm{CMV}$, varicella zoster virus (VZV), herpes simplex virus type 1 (HSV-1), and type 2 (HSV-2) and JC virus using nested PCR amplification with oligonucleotide primers to detect EBV internal repeats, CMV $g B, \mathrm{VZV}$ gene 29, HSV-1 $g D$, HSV-2 $g G$, and JC virus $\mathrm{T}$ antigen, as previously described. ${ }^{13} 22-25$ 
Table 1 Clinical and pathological diagnoses, CSF findings, MRI and SPET abnormalities

\begin{tabular}{|c|c|c|c|c|c|c|c|c|}
\hline \multirow[b]{2}{*}{$\begin{array}{l}\text { Patient } \\
\text { No }\end{array}$} & \multirow[b]{2}{*}{$\begin{array}{l}\text { Co-trimoxazole } \\
\text { prophylaxis }\end{array}$} & \multirow[b]{2}{*}{$\begin{array}{l}\text { Blood T gondii } \\
\text { serology (titre) }\end{array}$} & \multicolumn{2}{|l|}{ CSF } & \multicolumn{2}{|l|}{$M R I$} & \multicolumn{2}{|l|}{ SPET } \\
\hline & & & $\begin{array}{l}\text { gondii } \\
\text { serology }\end{array}$ & $\begin{array}{l}E B V \\
D N A\end{array}$ & $\begin{array}{l}\text { No of } \\
\text { lesions }\end{array}$ & Site & Site(s) of accumulation & $\begin{array}{l}\text { Uptake } \\
\text { ratio }(s)\end{array}$ \\
\hline \multicolumn{9}{|c|}{ Lymphoma, definite } \\
\hline 1 & No & - & - & + & 4 & $\begin{array}{l}(\mathrm{L})+(\mathrm{R}) \text { basal ganglia (periventricular) } \\
(\mathrm{L})+(\mathrm{R}) \text { temporal lobes, brain stem }\end{array}$ & $\begin{array}{l}\text { Periventricular, frontal white matter, } \\
\text { (R) parieto-occipital }\end{array}$ & $3.7-4.8$ \\
\hline 2 & No & - & - & + & 1 & (L) temporal lobe & (L) temporal & 2.1 \\
\hline 3 & Yes & - & Not don & & 1 & (R) thalamus and septum palucidium & (R) hemisphere midline & 3.3 \\
\hline 4 & Yes & $+(1: 1024)$ & Not don & & 1 & (R) fronto parietal & (R) frontoparietal & 4.0 \\
\hline 5 & No & - & Not don & & 1 & (L) temporal & $\begin{array}{l}\text { (L) temporal } \\
\text { latal }\end{array}$ & 6.6 \\
\hline 6 & Yes & - & Not don & & 2 & (R) occipital and (R) temporal & (R) occipital & 2.5 \\
\hline 7 & No & $+(1: 128)$ & Not don & & 1 & (R) parietal & (R) parietal & 7.0 \\
\hline 8 & No & - & Not don & & 2 & (L) basal ganglia & (L) perimedial hemisphere & 2.2 \\
\hline 9 & No & - & Not don & & 4 & $\begin{array}{l}\text { (R) thalamus, (L) basal ganglia } \\
\text { (L) cerebellar hemisphere }\end{array}$ & $\begin{array}{l}\text { (R) deep frontal and parietal } \\
\text { (L) cerebellar hemisphere }\end{array}$ & $\begin{array}{l}2.0 \\
3.0\end{array}$ \\
\hline \multicolumn{9}{|c|}{ Lymphoma, probable } \\
\hline 10 & Yes & - & \multicolumn{2}{|c|}{ Not done } & 4 & $\begin{array}{l}(\mathrm{L})+(\mathrm{R}) \text { frontal, }(\mathrm{R}) \text { temporal } \\
\text { (L) basal ganglia }\end{array}$ & $\begin{array}{l}\text { (L) frontal } \\
\text { (R) frontal }\end{array}$ & $\begin{array}{l}2.6 \\
3.4\end{array}$ \\
\hline 11 & Yes & - & \multicolumn{2}{|c|}{ Not done } & 10 & $\begin{array}{l}\text { (L) fronto parietal, (L) temporal } \\
\text { (L) }+(\mathrm{R}) \text { basal ganglia }\end{array}$ & (L) frontal & 3.4 \\
\hline 12 & Yes & - & \multicolumn{2}{|c|}{ Not done } & 2 & (L) occipital & (L) occipital & 3.1 \\
\hline 13 & No & - & \multirow{2}{*}{\multicolumn{2}{|c|}{$\begin{array}{l}\text { Not done } \\
\text { Not done }\end{array}$}} & 2 & (L) frontoparietal & (L) frontoparietal & $3.0-2.1$ \\
\hline 14 & Yes & - & & & 1 & brain stem, periventricular (IV ventricle) & (L) posterior fossa & 2.7 \\
\hline 15 & Yes & - & & 1 & (R) basal ganglia & Multiple, both hemispheres & 2.0 \\
\hline 16 & No & - & & & 10 & (R) frontal, $(\mathrm{L})+(\mathrm{R})$ basal ganglia & Multiple, both hemispheres & 1.9 \\
\hline 17 & No & - & \multicolumn{2}{|c|}{$\begin{array}{r}\text { Not done } \\
-\quad+\end{array}$} & 3 & $\begin{array}{l}\text { (R) frontal, (R) basal ganglia brain stem } \\
\text { (subependymal IV ventricle) }\end{array}$ & $\begin{array}{l}\text { (R) posterotemporal and } \\
\text { parieto-occipital }\end{array}$ & 1.5 \\
\hline 18 & Yes & - & - & + & 4 & $\begin{array}{l}\text { (L) frontal, (L) cerebellar hemisphere, } \\
\text { brain stem }\end{array}$ & None & 0 \\
\hline \multicolumn{9}{|c|}{ Lymphoma + Toxoplasma, definite } \\
\hline 19 & Yes & $+(1: 1024)$ & \multicolumn{2}{|c|}{ Not done } & $>14$ & $\begin{array}{l}\text { (R) occipital } \\
\text { (R) frontal }\end{array}$ & $\begin{array}{l}\text { (R) occipital } \\
\text { (R) Frontal }\end{array}$ & $\begin{array}{l}2.8 \\
7.6\end{array}$ \\
\hline \multirow{2}{*}{\multicolumn{2}{|c|}{$\begin{array}{l}20 \quad \text { No } \\
\text { Toxoplasmosis, probable }\end{array}$}} & - & - & + & 2 & (R) temporal, (R) basal ganglia & None & 0 \\
\hline & & & & & & & & \\
\hline 21 & Yes & - & - & - & $\begin{array}{l}1 \\
>20\end{array}$ & $\begin{array}{l}\text { (R) parietal } \\
\text { (L) cerebellar hemisphere, (L) basal } \\
\text { ganglia }\end{array}$ & Multiple scattered & 2.1 \\
\hline 22 & No & - & \multicolumn{2}{|c|}{ Not done } & 10 & $\begin{array}{l}\text { (R) frontal (L) temporal brain stem } \\
\text { (R) cerebellar hemishere }\end{array}$ & (R) hemisphere $(\times 3)$ & 2.1 \\
\hline 23 & No & - & \multicolumn{2}{|c|}{ Not done } & 10 & $\begin{array}{l}\text { (L)frontal (L) temporal (R) occipital } \\
\text { (L) basal galglia, pons }\end{array}$ & (L) posterior frontal & 1.9 \\
\hline 24 & No & - & \multicolumn{2}{|c|}{ Not done } & 2 & $(\mathrm{~L})+(\mathrm{R})$ basal ganglia & (R) frontoparietal & 1.7 \\
\hline 25 & Yes & - & \multicolumn{2}{|c|}{ Not done } & 10 & periventricular (II, III, and IV ventricles) & (L) posterior fossa & 1.5 \\
\hline 26 & Yes & $+(1: 256)$ & \multicolumn{2}{|c|}{ Not done } & 1 & (L) frontal & Multiple, both hemispheres & 1.4 \\
\hline 27 & No & - & \multicolumn{2}{|c|}{ Not done } & 10 & $\begin{array}{l}\text { (L) }+(\mathrm{R}) \text { basal ganglia } \\
\text { (L) cerebellar hemisphere, brian stem }\end{array}$ & None & 0 \\
\hline 28 & No & $+(1: 128)$ & \multicolumn{2}{|c|}{ Not done } & 3 & (R) frontal $(\mathrm{L})+(\mathrm{R})$ basal ganglia & None & 0 \\
\hline 29 & Yes & - & \multicolumn{2}{|c|}{ Not done } & 3 & $\begin{array}{l}\text { (L) frontal }(\mathrm{L}) \text { temporal }(\mathrm{L})+(\mathrm{R}) \text { basal } \\
\text { ganglia }\end{array}$ & None & 0 \\
\hline 30 & No & $+(1: 1024)$ & Not don & & 10 & $\begin{array}{l}\text { (R) frontal, }(\mathrm{R}) \text { temporal }(\mathrm{R}) \text { cerebellar } \\
\text { hemisphere } \\
(\mathrm{L})+(\mathrm{R}) \text { basal ganglia, brain stem } \\
\text { (periventricular) }\end{array}$ & None & 0 \\
\hline 31 & Yes & $+(1: 1024)$ & - & - & $5-10$ & $\begin{array}{l}\text { (L) frontal (R) occiptal (L) cerebellar } \\
\text { hemisphere, } \\
\text { (R) basal ganglia }\end{array}$ & None & 0 \\
\hline 32 & No & - & Not don & & $5-10$ & $\begin{array}{l}\text { (R) parietal, }(\mathrm{L}) \text { temporal } \\
(\mathrm{L})+(\mathrm{R}) \text { basal ganglia (subependymal } \\
\text { around lateral ventricles }\end{array}$ & None & 0 \\
\hline
\end{tabular}

+ = positive; - = negative; $\mathrm{EBV}=$ Epstein-Barr virus; $\mathrm{L}=$ left; $\mathrm{R}=$ right.

Six patients had CT guided stereotactic brain biopsy and six had necropsy (two had both). All necropsies were performed by SBL. Neuropathological examination of necropsy tissue was performed by SBL and FS and brain biopsy tissue by FS. A protocol as previously described was used. ${ }^{6}$ In addition, tissue was specifically examined for evidence of (a) lymphoma-identified by the presence of aggregations of pleomorphic lymphocytes either diffusely infiltrating the brain tissue or angiocentric in distribution. In addition, immunocytochemistry was performed using the B lymphocyte marker L26 (1:250; Dako Ltd, High Wycombe) and UCLH-1 (T lymphocyte marker; 1:250; Dako Ltd, High Wycombe). All lymphomas were L26 positive; (b) toxoplasmosis-identified by necrotising abscess formation with infiltration of inflammatory cells and macrophages with the presence of $T$ gondii organisms on routine haematoxylin and eosin stain and/or immunohistochemical staining with polyclonal antibodies for $T$ gondii (1:150; ICN Pharmaceuticals, Thame).

The following definitions were used for diagnosis:

Toxoplasmosis, probable: typical cranial MRI appearances of single or multiple focal lesions with gadolinium enhancement and/or surrounding vasogenic oedema with partial or complete response to anti-toxoplasmosis therapy (without use of corticosteroids) seen on follow up MRI. ${ }^{16}$

Toxoplasmosis, definite: as above, with histological confirmation by necropsy.

Lymphoma, probable: MRI appearances (as above) failing to respond to anti-toxoplasmosis therapy, with or without detectable EBV DNA in CSF. ${ }^{16}$ 
Lymphoma, definite: as above, with histological confirmation by brain biopsy and/or necropsy.

Results of MRI and ${ }^{201} \mathrm{Tl}$ SPET were compared using a two tailed Fisher's exact test. In those with toxoplasmosis the possible effect of duration of anti-toxoplasma therapy on ${ }^{201} \mathrm{Tl}$ SPET accumulation was assessed by the Mann-Whitney U test. A p value of $<0.05$ was considered significant.

\section{Results}

There were nine cases of definite lymphoma, nine cases of probable lymphoma, and 12 cases of probable toxoplasmosis. Two further cases had definite toxoplasmosis and lymphoma. In those with probable lymphoma, while the diagnosis was not confirmed histologically, the MRI appearances failed to respond to antitoxoplasma therapy and were atypical for cryptococcomas, which do not enhance with gadolinium and have no surrounding oedema, ${ }^{26}$ and for progressive multifocal leucoencephalopathy, as these lesions do not enhance and exert no mass effect. ${ }^{27}$ The absence of associated basal meningeal enhancement makes tuberculosis an unlikely possibility. During the study period 11 other patients presented with focal CNS lesions due to lymphoma (six patients) or toxoplasmosis (five patients). They were not included in this study as assessment of response was made unreliable because eight patients (including all six with lymphoma) were given dexamethasone at presentation, because of obtundation and/or cerebral oedema or midline shift on MRI, and of the other three patients with probable toxoplasmosis, one withdrew from treatment and died, one was non-compliant with the imaging protocol, and one developed severe drug toxicity and treatment was temporarily discontinued.

Table 1 gives results from MRI, ${ }^{201} \mathrm{Tl}$ SPET, and CSF analyses, together with the patients' clinical and pathological diagnoses. In reporting the MRI appearances there was agreement for 29 patients and a consensus in three patients.

$\mathrm{CSF}$ analysis performed in eight patients revealed no detectable CMV, VZV, HSV-1, HSV-2, or JC virus DNA in any patient. EBV DNA was detected in six patients, three with definite and three with probable lymphoma and none with toxoplasmosis (table 1). Lymphoma blast cells were detected in CSF of one patient (No 2, table 1).

Of those with lymphoma three were taking co-trimoxazole as prophylaxis against PCP, as was one patient with both toxoplasmosis and lymphoma, and five of those with toxoplasmosis (table 1). T gondii IgG antibodies were detected in seven patients, two of whom had definite lymphoma and one who had both toxoplasmosis and lymphoma at necropsy. In one patient (No 31) with toxoplasmosis, although IgG antibodies were detectable in serum at a titre of 1:1024, no antibodies were detected in CSF. No patient had detectable IgM antibodies in serum.
In patient No 9 the diagnosis of lymphoma was made on histological examination of tissue from a stereotactic biopsy of the cerebellar lesion; a second lesion in the deep frontoparietal region was not biopsied. At necropsy in patient No 19, the right frontal lesion consisted of lymphoma, whereas the right occipital lesion was due both to lymphoma and a healed toxoplasma abscess. In patient No 20 the right basal ganglia lesion was lymphoma and the right temporal lobe lesion was a healed toxoplasma abscess (table 1).

Cranial MRI of 23 patients showed multiple lesions (table 1), in the remainder a single lesion was demonstrated. Eight patients with lymphoma and one patient with toxoplasmosis had single lesions, $\mathrm{p}=0.044$, two tailed Fisher's exact test. The interval between cranial MRI and ${ }^{201}$ T1 SPET scanning ranged between 1 and 25 (median 7) days.

SPET scanning showed focal accumulation of ${ }^{201} \mathrm{Tl}$ in 24 patients. No significant difference was noted between the two cameras for detection of uptake in deep lesions. Only one of 18 lymphoma cases had no focal accumulation while six of the 12 with toxoplasmosis showed no uptake, $p=0.034$, two tailed Fisher's exact test. One patient with both lymphoma and toxoplasmosis had no focal accumulation of ${ }^{201} \mathrm{Tl}$. In those with focal accumulation uptake ratios varied widely (table 1 ). In those with lymphoma (including the two patients with both lymphoma and toxoplasmosis) uptake ratios ranged from 0 to 7.6 (median 2.85) and of those with toxoplasmosis uptake ratios ranged from 0 to 2.1 (median 0.7 ). Of the 18 patients with lymphoma, six patients had one or more lesions seen on MRI which were $\leqslant 18 \mathrm{~mm}$ and did not accumulate ${ }^{201} \mathrm{Tl}$ (table 1 ). If the criteria used by O'Malley et $a l^{17}$ are applied to these data and an uptake ratio of $\geqslant 2.9$ is taken to represent lymphoma, then this finding has a sensitivity of $55 \%$, a specificity of $100 \%$, and a negative predictive value of $57 \%$ for diagnosis of lymphoma. In addition if an uptake ratio of $\leqslant 2.0$ is used to determine which patients have toxoplasmosis, ${ }^{16}$ this finding has a sensitivity of $83 \%$, a specificity of $75 \%$, and a negative predictive value of $88 \%$. Of eight patients with single lesions on MRI and focal accumulation of ${ }^{201} \mathrm{Tl}$ only one proved to be toxoplasmosis.

In all but two patients (Nos 2 and 6) anti-toxoplasma therapy had been commenced at the time of SPET scanning, median 7 days (range 1-42 days). In those patients with toxoplasmosis, if those who had received $\leqslant 7$ days anti-toxoplasma therapy are compared with those who had received $>7$ days treatment, no differences in ${ }^{201} \mathrm{Tl}$ SPET ratios were observed: Mann-Whitney U test ( $\mathrm{p}=\mathrm{NS}$ ).

\section{Discussion}

This study has sought to define the accuracy with which focal CNS lesions due to lymphoma can be distinguished from toxoplasmosis by neuroimaging using MRI and ${ }^{201} \mathrm{Tl}$ SPET, and laboratory investigations including CSF analysis. The study population consisted of a selected series of patients infected with 
HIV and well documented neurological presentations. The results show that the MRI findings of single or multiple focal lesions can represent either lymphoma or toxoplasmosis, with both kinds of lesions showing ring or other patterns of enhancement. This lack of discrimination using MRI has previously been reported and our observations are confirmatory. ${ }^{112}$ However certain specific MRI abnormalities in our study were strongly suggestive of lymphoma-for example, if lesions were single or were periventricular in location and demonstrated subependymal spread. These clinically useful appearances were only present in a minority however.

In our study seven of 32 patients had positive serology for toxoplasmosis. Eight of the 14 patients with toxoplasmosis had no detectable IgG antibodies and, in contrast, two with histologically confirmed lymphoma and no toxoplasmosis had positive serology. Thus we were unable to use toxoplasma serology to aid discrimination between diagnoses. Similarly we found that knowledge of patients' use of prophylaxis with co-trimoxazole did not aid discrimination. These data contrast with those from a recent study of $97 \mathrm{HIV}$ infected patients from Rome ${ }^{11}$ where toxoplasma serology was positive in $97 \%$ of those with toxoplasmosis and in only $31 \%$ with lymphoma. Using a decision making analysis model and applying Bayes' theorem, it was found in those patients with positive toxoplasma serology who were not taking anti-P carinii prophylaxis which was also effective against toxoplasmosis, the probability of toxoplasmosis was 0.87 , but was only 0.59 if prophylaxis was given. In those with negative toxoplasma antibodies the probability of lymphoma was 0.74 . Several other studies have suggested that, in the HIV infected population, possession of IgG antibodies is strongly associated with the development of toxoplasmosis. ${ }^{28-30}$ Interpretation of these data is confounded by widely varying rates of seroprevalence in the general population in different geographical locations. In France approximately $75 \%$ of adults have antibodies where as in the United States and the United Kingdom the rate is approximately $25 \%$.

In those patients in our study, in whom lumbar puncture was carried out, EBV DNA detection was strongly associated with CNS lymphoma. However we were only able to perform CSF analysis in $8 / 32(25 \%)$ of our patients. In the study from Rome ${ }^{11}$ CSF was obtained in only $38 / 97(40 \%)$ of patients. In that study, if EBV DNA was detected in CSF then the probability of lymphoma was 0.96 . These data and those from our own study underscore the fact that although genome detection from CSF is a highly sensitive and specific technique for diagnosis, ${ }^{13}{ }^{14}$ any such molecular diagnostic strategy is limited by the inability to perform lumbar puncture in a proportion of patients with focal CNS lesions because of contraindications such as mass effect.

In our study we found focal accumulation of ${ }^{201} \mathrm{Tl}$ in all but one of the 18 patients with lymphoma, and in one of the two patients with lymphoma and toxoplasmosis; in contrast, accumulation was seen in only half of those with toxoplasmosis. High uptake ratios, $\geqslant 2.9$, were only found in those with lymphoma; however, some patients with lymphoma had lower uptake ratios, between 1.5 and 2.1 , as did patients with toxoplasmosis. These data contrast with a previous study which suggested that measurements of the uptake ratios in those with focal accumulation of ${ }^{201} \mathrm{Tl}$ aided discrimination between lymphoma and toxoplasmosis. ${ }^{17}$ In this study, from Washington, of 13 HIV infected patients with focal CNS lesions on MRI six patients had ${ }^{201} \mathrm{Tl}$ uptake ratios (calculated using a method similar to ours) of between 2.95 and 4.30 (mean 3.65): all these patients had lymphoma. Seven patients had uptake ratios ranging from 0.77 to 1.95, five had toxoplasmosis (one also had CMV and Mycobacterium tuberculosis), one had progressive multifocal leucoencephalopathy, and one had a venous angioma.

In a prospective study from Miami $37 \mathrm{HIV}$ infected patients with focal CNS lesions on cranial CT or MRI also had imaging with ${ }^{201} \mathrm{Tl}$ SPET. ${ }^{18}$ Intense focal accumulation was seen only in 12 patients, all of whom had biopsy or necropsy confirmed lymphoma. No accumulation of ${ }^{201} \mathrm{Tl}$ was seen in the other 25 patients, of whom 24 had toxoplasmosis. ${ }^{18}$

In a third study from New York, 18 HIV infected patients with focal CNS lesions underwent ${ }^{201}$ Tl SPET imaging..$^{19}$ In this study 10 patients had focal accumulation of ${ }^{201} \mathrm{Tl}$ in focal CNS lesions shown by CT/MRI with uptake ratios of between 2.1 and 30.6. Of these five had biopsy proved lymphoma, three had probable lymphoma (using criteria similar to those used in our study), one had metastatic adenocarcinoma, and one had probable toxoplasmosis. Eight other patients had no accumulation of ${ }^{201} \mathrm{Tl}$; of these seven had toxoplasmosis (six by clinical response, one confirmed by biopsy) and one had a cryptococcoma.

These three studies differed from ours in several ways. Firstly, ${ }^{201} \mathrm{Tl}$ SPET was performed in the majority of patients within 72 hours of CT or MRI.$^{17-19}$ In our study ${ }^{201} \mathrm{Tl}$ SPET was carried out a median of 7 (range 1-25) days after MRI. Secondly, the imaging protocol in two of the studies used higher doses of radiotracer and imaged more rapidly after intravenous injection of ${ }^{201} \mathrm{Tl}$. Imaging was 5 minutes after $5 \mathrm{mCi}^{201} \mathrm{Tl}$ in one study ${ }^{18}$ and 10 minutes after $4 \mathrm{mCi}$ in the other. ${ }^{19}$ However, the study ${ }^{17}$ which showed ${ }^{201} \mathrm{Tl}$ SPET to clearly discriminate between lymphoma and toxoplasmosis used an identical imaging protocol to ours. The third difference lies in the patients themselves. In our study of eight patients with single lesions on MRI and focal accumulation of ${ }^{201} \mathrm{Tl}$ seven had lymphoma. These seven patients all had uptake ratios $\geqslant 2.0$ which enabled discrimination from the patient with toxoplasmosis to be made as in this case the uptake ratio was only 1.4 . In the study from Washington ${ }^{17}$ all 13 patients had only single focal CNS lesions on MRI. In the study from Miami ${ }^{18}$ of the 37 patients 13 had a single mass lesion. Accumulation was seen only in the seven with lymphoma and not in the six 
with toxoplasmosis. Eight of the 18 patients in the study from New York $^{19}$ had single mass lesions; focal accumulation occurred in all three with lymphoma as the cause, one of three with toxoplasmosis, and one patient with adenocarcinoma.

Other nuclear medicine techniques have been used to aid discrimination between toxoplasmosis and lymphoma including technetium-99m Sestamibi $\quad\left({ }^{99} \mathrm{Tc}^{\mathrm{m}} \quad \mathrm{MIBI}\right)$ SPET, ${ }^{31}$ and fluorine-18 fluorodeoxyglucose positron emission tomography $\left({ }^{18} \mathrm{FDG}\right.$ PET $) .{ }^{32}$ SPET with ${ }^{99} \mathrm{Tc}^{\mathrm{m}}$ MIBI was compared with ${ }^{201} \mathrm{Tl}$ in a study of $17 \mathrm{HIV}$ infected patients with focal CNS lesions (four had biopsy proved lymphoma). For diagnosis of lymphoma both techniques had $100 \%$ sensitivity but a specificity and negative predictive value of $69 \%$ and $54 \%$ for ${ }^{99} \mathrm{Tc}^{\mathrm{m}}$ MIBI and $54 \%$ and $40 \%$ for ${ }^{201} \mathrm{Tl}^{31}$ The higher preferential uptake by the choroid plexus of ${ }^{99} \mathrm{Tc}^{\mathrm{m}}$ MIBI compared with ${ }^{201} \mathrm{Tl}$ means that in HIV infected patients it is more difficult to evaluate focal CNS lesions which are paraventricular in location as may occur in cerebral lymphoma. ${ }^{31}{ }^{18}$ FDG PET which can measure regional metabolic activity accurately discriminates between toxoplasmosis and lymphoma (and other conditions including progressive multifocal leucoencephalopathy). ${ }^{32}$ The disadvantage of this technique is that it is not available in the majority of centres and it is more expensive than ${ }^{201}$ Tl SPET scanning.

In conclusion, in our study knowledge of patients' toxoplasma serology and use of co-trimoxazole for PCP did not aid discrimination between lymphoma and toxoplasmosis. Detection of EBV DNA in CSF was strongly associated with lymphoma but this molecular diagnostic strategy was limited by our inability to perform lumbar puncture in $75 \%$ of patients. Although many of the findings on MRI were non-discriminatory a single focal lesion was likely to represent lymphoma. In those with single focal lesions on MRI quantitative assessment of focal accumulation of ${ }^{201} \mathrm{Tl}$ was useful in differentiating lymphoma from toxoplasmosis. In those with multiple lesions on $\mathrm{MRI}{ }^{201} \mathrm{Tl}$ was useful in identifying lymphoma in patients with uptake ratios $\geqslant 2.9$; in those with uptake ratios $\leqslant 2.1{ }^{201} \mathrm{Tl}$ did not aid discrimination. In these patients an empirical trial of antitoxoplasma therapy is indicated. In those who fail to respond stereotactic brain biopsy remains an option. However, factors including the underlying condition of the patient, accessibility of lesions to biopsy, and decisions about which lesion to biopsy, together with the morbidity and mortality associated with the procedure should be considered carefully. ${ }^{11}$

We thank Teresa Fullam for typing the manuscript and Andrew Copas for statistical advice. FS acknowledges financial support from the Brain Research Trust.

Conflict of interests: None.

A detailed description of the MRI appearances of the patients in this study is held on file in the STI office and is available to interested readers.

Contributors: All authors contributed significantly to the writing of early drafts of the manuscript, the correction and modifying of subsequent drafts, and to the creation of the final version. Professor S B Lucas and Professor F Scaravilli performed the Professor S B Lucas and Professor F Scaravilli performed the
necropsies and histopathological assessments. Dr D C Costa necropsies and histopathological assessments. Dr D C Costa
analysed and interpreted SPET images. Dr I Wilkinson blinded the MRI scans and facilitated the blind re-reporting of these scans by Drs Hall-Craggs and Kendall. Dr N Brink supervised the carrying out of PCR work on the CSF samples and interpreted the findings. The study was designed and initiated by Dr R F Miller, who was responsible for clinical data collection and for writing the original draft together with Dr I Wilkinson, Professor M Harrison, and Professor P Ell.

1 Snider WD, Simpson DM, Nielson S, et al. Neurological complications of acquired immune deficiency syndrome: analysis of 50 patients. Ann Neurol 1983;14:403-18.

2 Levy RM, Bredesen DE, Rosenblum ML. Neurological manifestations of the acquired immunodeficiency syndome (AIDS): experience at UCSF and review of the literature. $\mathcal{F}$ Neurosurg 1985;62:475-95.

3 Bacellar H, Munoz A, Miller EN. Temporal trends in the incidence of HIV-1 related neurologic diseases: multicentre AIDS cohort study, 1985-1992. Neurology 1994;44:1892900 .

4 Budka H, Wiley C, Kleihues P, et al. HIV-associated disease of the nervous system: review of nomenclature and proposal for neuropathology-based terminology. Brain Pathol 1991;1:143-52.

5 Holland NR, Power C, Mathews VP, et al. Cytomegalovirus encephalitis in acquired immunodeficiency syndrome (AIDS). Neurology 1994;44:507-14.

6 Miller RF, Lucas SB, Hall-Craggs MA, et al. Comparison of magnetic resonance imaging with neuropathological findings in the diagnosis of HIV and CMV associated CNS disease in AIDS. F Neurol Neurosurg Psychiatry 1997;62: 346-51.

7 Luft BJ, Hafner R, Korzun AH. Toxoplasmic encephalitis in patients in the acquired immune deficiency syndrome. $N$ patients in the acquired immun
Engl f Med 1993;329:995-1000.

8 Rosemblum ML, Levy RM, Bredesen DE, et al. Primary central nervous system lymphomas in patients with AIDS. Ann Neurol 1988;23(Suppl):S13-16.

9 Cordoliani Y-S, Derosier C, Pharaboz C, et al. Primary cerebral lymphoma in patient with AIDS:MR findings in 17 cases. Am f Roentg 1992;159:841-7.

10 Dina TS. Primary central nervous system lymphoma versus toxoplasmosis in AIDS. Radiology 1991;179:823-8.

11 Antinori A, Ammassari A, DeLuca A, et al. Diagnosis of AIDS-related focal brain lesions: a decision making analysis based on clinical and neuroradiologic characteristics combined with polymerase chain reaction assays in CSF. Neurology 1997;48:687-94.

12 Chappell ET, Guthrie BL, Orenstein J. The role of sterotactic biopsy in the management of HIV-related focal brain lesions. Neurosurgery 1992;30:825-9.

13 Cinque P, Brythine M, Vago L, et al. Epstein-Barr virus DNA in cerebrospinal fluid from patients with AIDSrelated primary lymphoma of the central nervous system. related primary lymphoma
Lancet 1993;342:398-401.

14 d'Arminio Monforte A, Cinque P, Vago L, et al. A comparison of brain biopsy and CSF-PCR in the diagnosis of CNS lesions in AIDS patients. $\mathcal{F}$ Neurol 1997;244:35-9.

15 Cingolani A, DeLuca A, Ammassari A. PCR detection of Toxoplasma gondii-DNA in CSF for the differential diagnosis of AIDS-related focal brain lesions. 7 Med Microbiol 1996;45:472-6.

16 Chinn RJS, Wilkinson ID, Hall-Craggs MA, et al. Toxoplasmosis and primary central nervous system lymphoma in HIV infection: diagnosis with MR spectroscopy. Radiology 1995;197:640-54.

17 O'Malley JP, Ziessman HA, Kumar PN, et al. Diagnosis of intracranial lymphoma in patients with AIDS: value of ${ }^{201} \mathrm{Tl}$ single photon emission computed tomography. $A m \mathcal{F}$ single photon emission

18 Ruiz A, Ganz WI, Post JD, et al. Use of thallium-201 brain SPECT to differentiate cerebral lymphoma from toxoplasma encephalitis in AIDS patients. Am $\mathcal{f}$ Neuroradiol 1994;15:1885-94.

19 Loyerboym M, Estok L, Machac J, et al. Rapid differential diagnosis of cerebral toxoplasmosis and primary central nervous system lymphoma by thallium-201 SPECT. $\mathcal{F} \mathrm{Nucl}$ Med 1996;37:1150-4.

20 Black KL, Hawkins RA, Kim KT, et al. Use of ${ }^{201} \mathrm{Tl}$ SPECT to quantitate malignancy grade of gliomas. I Neurosurg 1989;71:342-6.

21 D'Amico A, Messa C, Castagna A, et al. Diagnostic accuracy and predictive value of ${ }^{201} \mathrm{Tl}$ SPET for the differential diagnosis of cerebral lesions in AIDS patients. Nucl Med Commun 1997;18:741-50.

22 Mitchell SM, Fox JD, Tedder RS, et al. Vitreous sampling and viral genome detection for the diagnosis of viral retinitis. F Med Virol 1994;40:336-40.

23 Grant AD, Fox JD, Brink NS, et al. Detection of varicella-zoster virus DNA using the polymerase chain reaction in an immunocompromised patient with transverse myelitis secondary to herpes zoster. Genitourin Med 1993;69:273-5.

24 Aurelius E, Johansson B, Skoldenberg B, et al. Encephalitis in immunocompetent patients due to herpes simplex type 1 or 2 as determined by type-specific polymerase chain reaction and antibody assays of the cerebrospinal fluid. $\mathcal{F} \mathrm{Med}$ Virol 1993;39:179-86.

25 Perrons CJ, Fox JD, Lucas SB, et al. Detection of polyomaviral DNA sequences by the nested polymerase chain reaction in clinical samples from immunocompromised patients. F Infection 1996;32:205-9.

26 Mizkiel KA, Hall-Craggs, Miller RF, et al. The spectrum of MRI findings in CNS cryptococcosis in AIDS. Clin Radiol 1996;51:842-50. 
27 Hansman Whiteman ML, Dononvan Post MJ, Berger JR, et al. Progressive multifocal leukoencephalopathy in 47 HIVseropositive patients:neuroimaging with clinical and pathologic correlation. Radiology 1993;187:233-40.

28 Grant IH, Gold JWM, Rosenblum M, et al. Toxoplasma gondii serology in HIV-infected patients: the development of central nervous system toxoplasmosis in AIDS. AIDS 1990;4:519-21.

29 Raffi F, Aboulker JP, Michelet C, et al. A prospective study of criteria for the diagnosis of toxoplasmic encephalitis in 186 AIDS patients. AIDS 1997;11:177-84.
30 Hellerbrand C, Goebel FD, Disko R. High predictive value of Toxoplasma gondii IgG antibody levels in HIV-infected patients for diagnosis for cerebral toxoplasmosis. Eur f Clin Microbiol Infect Dis 1996;15:869-72.

31 Naddaf SY, Akisik MF, Aziz M, et al. Comparison between ${ }^{201}$ Tl-chloride and ${ }^{99} \mathrm{~T}^{\mathrm{cm}}$ - Sestamibi SPET brain imaging for differentiating intercranial lymphoma from nonmalignant lesions in AIDS patients. Nucl Med Commum 1998;19:47-53.

32 O'Doherty MJ, Barrington SF, Campbell M, et al. PET scanning and the human immunodeficiency virus-positive patient. F Nucl Med 1997;38:1575-83. 